\title{
The Role of Monitoring Arterial Stiffness with Cardio-Ankle Vascular Index in the Control of Lifestyle-Related Diseases
}

\author{
Kohji Shirai ${ }^{a, d} \quad$ Atsuhito Saiki $^{b} \quad$ Daiji Nagayamab $^{b} \quad$ Ichiro Tatsuno $^{b}$ \\ Kazuhiro Shimizuc Mao Takahashic \\ ${ }^{a}$ Department of Vascular Function, ${ }^{b}$ Diabetes Endocrine and Metabolism Center, and \\ ${ }^{\mathrm{c} C a r d i o v a s c u l a r}$ Center, Sakura Hospital, School of Medicine, Toho University, and d Seijinkai \\ Mihama Hospital, Chiba, Japan
}

\section{Key Words}

Arterial stiffness - Cardiac dysfunction - Cardio-ankle vascular index · Coronary risk factor . Hypertension · Diabetes mellitus · Arteriosclerosis · Pulse wave velocity

\begin{abstract}
Arteriosclerosis is a major contributor to cardiovascular diseases. One of the difficulties in controlling those diseases is the lack of a suitable indicator of arteriosclerosis or arterial injury in routine clinical practice. Arterial stiffness was supposed to be one of the monitoring indexes of arteriosclerosis. Cardio-ankle vascular index (CAVI) is reflecting the stiffness of the arterial tree from the origin of the aorta to the ankle, and one of the features of CAVI is independency from blood pressure at a measuring time. When doxazosin, an $\alpha_{1}$-adrenergic blocker, was administered, CAVI decreased, indicating that arterial stiffness is composed of both organic stiffness and functional stiffness, which reflects the contraction of arterial smooth muscle. CAVI shows a high value with aging and in many arteriosclerotic diseases, and is also high in persons possessing main coronary risk factors such as diabetes mellitus, metabolic syndrome, hypertension and smoking. Furthermore, when the most of those risk factors were controlled by proper methods, CAVI improved. Furthermore, the co-relationship between CAVI and heart function was demonstrated during treatment of heart failure. This paper reviews the principle and rationale of CAVI, and discusses the meaning of monitoring CAVI in following up so-called lifestyle-related diseases and cardiac dysfunction in routine clinical practice.

(c) 2015 S. Karger AG, Basel
\end{abstract}


Shirai et al.: The Role of Monitoring Arterial Stiffness with Cardio-Ankle Vascular Index in the Control of Lifestyle-Related Diseases

\section{Introduction}

Arteriosclerosis is a major contributor to cardiovascular diseases, which account for a considerable part of mortality and morbidity $[1,2]$. It is almost established that hypertension, diabetes mellitus, smoking and dyslipidemia play a major role in the initiation and development of arteriosclerosis. One of the difficulties in controlling those risk factors is the lack of a suitable indicator of arteriosclerosis or arterial injury in addition to laboratory data values in routine clinical practice. Arterial stiffness was supposed to be one candidate of the monitoring index of arteriosclerosis [3-5], and several methods have been designed to assess arterial stiffness, including pulse wave velocity (PWV) [3, 4]. As for PWV, there have been many methods such as carotid-femoral PWV [6], heart-to-femoral PWV [7] and brachialankle PWV (baPWV) [8, 9]. Monitoring arterial stiffness as a surrogate marker of arteriosclerosis was nearly established using various kinds of PWV $[6,10]$. However, PWV essentially depends on blood pressure at the time of measurement [11]. Then, the stiffness of the artery is not accurately evaluated in individuals whose blood pressure was changed by drug therapy or lifestyle changes. To overcome this problem, cardio-ankle vascular index (CAVI) was developed [12]. CAVI reflects the stiffness of the arterial tree from the origin of the aorta to the ankle. CAVI is essentially derived from the stiffness parameter $\beta$, which was developed by Hayashi et al. [13] and Kawasaki et al. [14]. To apply the stiffness parameter $\beta$ to some length of artery, the equation of Bramwell-Hill in which the arterial volume change is related to PWV of the artery, was utilized [15]. Therefore, CAVI is independent of blood pressure at a measuring time and could reflect the proper stiffness of the arterial tree $[12,16]$. When doxazosin, an $\alpha_{1}$-adrenergic blocker which relaxes arterial smooth muscle, was administered, CAVI decreased [16]. This result indicated that arterial stiffness is composed of both organic stiffness and functional stiffness. Organic stiffness might be mainly composed of collagens, elastin and hyaluronic acid. Functional stiffness might reflect the contraction of arterial smooth muscle.

CAVI shows a high value with aging [17] and in many arteriosclerotic diseases [18-20], and is also high in persons possessing main coronary risk factors such as diabetes mellitus [21], metabolic syndrome [22], hypertension [23] and smoking [24]. Furthermore, when those risk factors were controlled by proper methods, CAVI improved [25-27]. Thus, monitoring CAVI might be useful for controlling lifestyle-related diseases in routine clinical practice. Furthermore, the co-relationship between CAVI and cardiac function has been demonstrated $[28,29]$.

This paper reviews the principle and rationale of CAVI, referring to the recently published data, and discusses the meaning of monitoring CAVI in following up so-called lifestyle-related disease and cardiac dysfunction in routine clinical practice.

\section{The Principle of CAVI}

CAVI reflects the stiffness of the whole arterial segment comprising the aorta, femoral artery and tibial artery (fig. 1). This index was originally derived from the stiffness parameter $\beta$ proposed by Hayashi et al. [13] and was expanded to some length of the artery with the application of the modified Bramwell-Hill equation [15]:

$$
\mathrm{CAVI}=\mathrm{a}\left[(2 \rho / \Delta \mathrm{P}) \times \ln (\mathrm{Ps} / \mathrm{Pd}) \times \mathrm{PWV}^{2}\right]+\mathrm{b},
$$

where Ps is systolic blood pressure, $\mathrm{Pd}$ is diastolic blood pressure, $\mathrm{PWV}$ is from the origin of the aorta to the tibial artery at the ankle through the femoral artery, $\Delta \mathrm{P}$ is $\mathrm{Ps}-\mathrm{Pd}, \rho$ is blood density and $a$ and $b$ are constants. 
Shirai et al.: The Role of Monitoring Arterial Stiffness with Cardio-Ankle Vascular Index in the Control of Lifestyle-Related Diseases

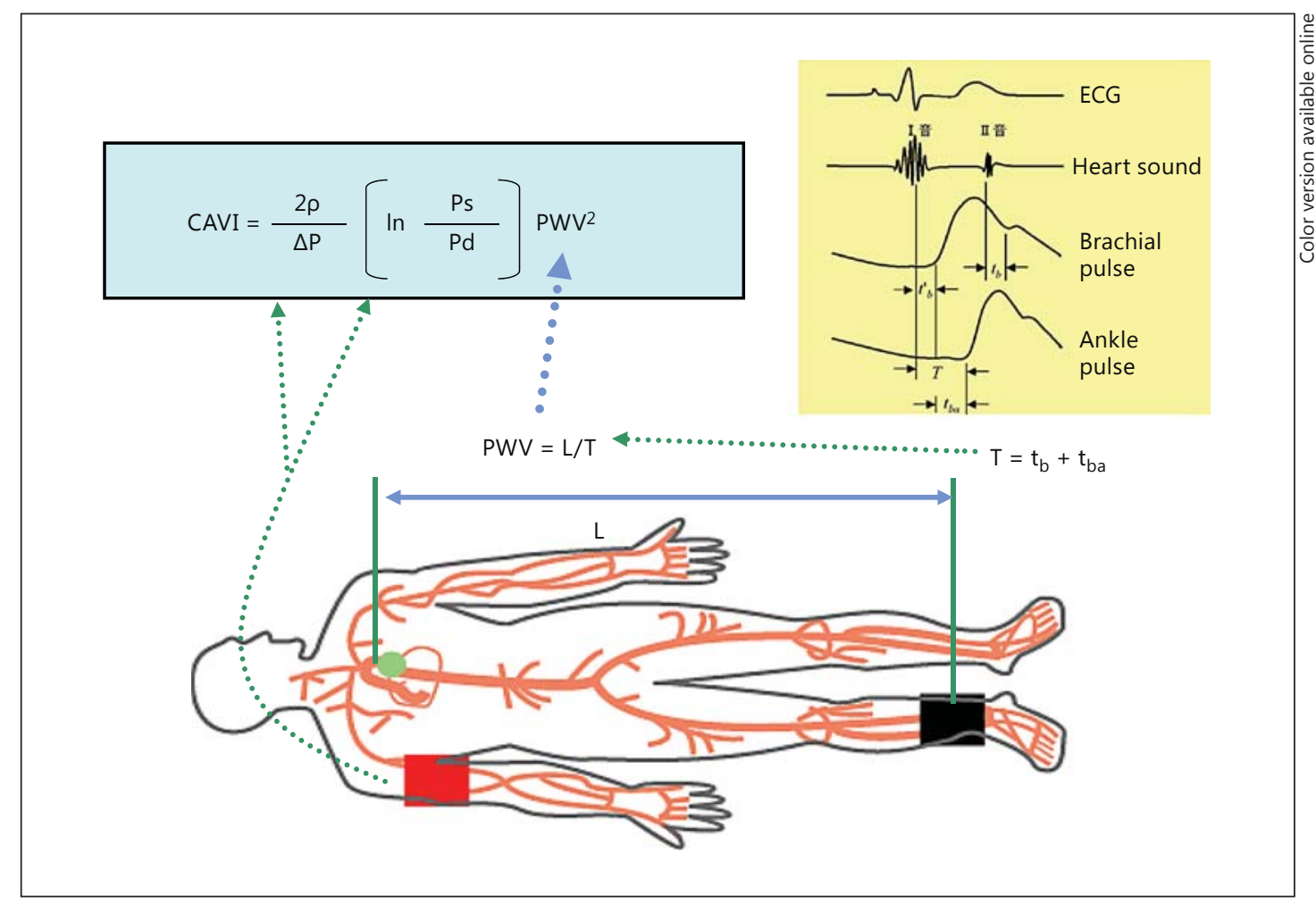

Fig. 1. The equation of CAVI and its measuring method. PWV from the heart to the ankle is obtained by measuring the length from the origin of the aorta to the ankle, and by calculating $T=t_{b}+t_{b a}$. Blood pressure is measured at the brachial artery. $\mathrm{Ps}=$ Systolic blood pressure; $\mathrm{Pd}=$ diastolic blood pressure; $\Delta \mathrm{P}=$ pulse pressure, Ps - Pd; $\rho$ = blood density; $L=$ length from the origin of the aorta to the ankle; $\mathrm{T}=$ time taken for the pulse wave to propagate from the aortic valve to the ankle; $t_{\mathrm{ba}}=$ time between the rise of brachial pulse wave and the rise of ankle pulse wave; $t_{b}=$ time between aortic valve closing sound and the notch of brachial pulse wave; $t_{b}^{\prime}=$ time between aortic valve opening sound and the rise of brachial pulse wave. Reproduced from Shirai et al. [12].

Thus, CAVI originates from stiffness parameter $\beta=\ln (\mathrm{Ps} / \mathrm{Pd}) \times(\mathrm{D} / \Delta \mathrm{D}) . \mathrm{D} / \Delta \mathrm{D}$ is calculated from $P W V$ of some length of the artery, and $\Delta P$ in place of diameter change $(D / \Delta D)$.

As for the application of blood pressure of the upper brachial artery in the calculation of the CAVI equation, there is an assumption that blood pressure at the upper brachial artery is nearly the mean of the blood pressure from the origin of the aorta to the tibial artery at the ankle. This is one of the limitations of CAVI. Therefore, in cases where the blood pressures at the aorta and the femoral artery were remarkably changed, such as in the case of femoral arterial arteriosclerosis obliterans $(\mathrm{ABI}<0.9)$, the CAVI value is invalid. Also, it is wrong to measure CAVI in the standing position. In this case, blood pressure at the ankle and brachial artery is quite different.

Independence of CAVI from blood pressure has been supported not only theoretically but also experimentally. Experimental evidence is demonstrated in figure 2a [16]. When the selective $\beta_{1}$-blocker metoprolol, which decreases blood pressure by decreasing heart muscle contractility and cardiac output, but not by affecting vascular wall contractility, was administered to men, systolic and diastolic blood pressure decreased for $6 \mathrm{~h}$. During this time, CAVI did not change and baPWV decreased. This phenomenon could be explained as follows: CAVI does not change because metoprolol does not affect the contracture of arterial wall smooth 
Shirai et al.: The Role of Monitoring Arterial Stiffness with Cardio-Ankle Vascular Index in the Control of Lifestyle-Related Diseases

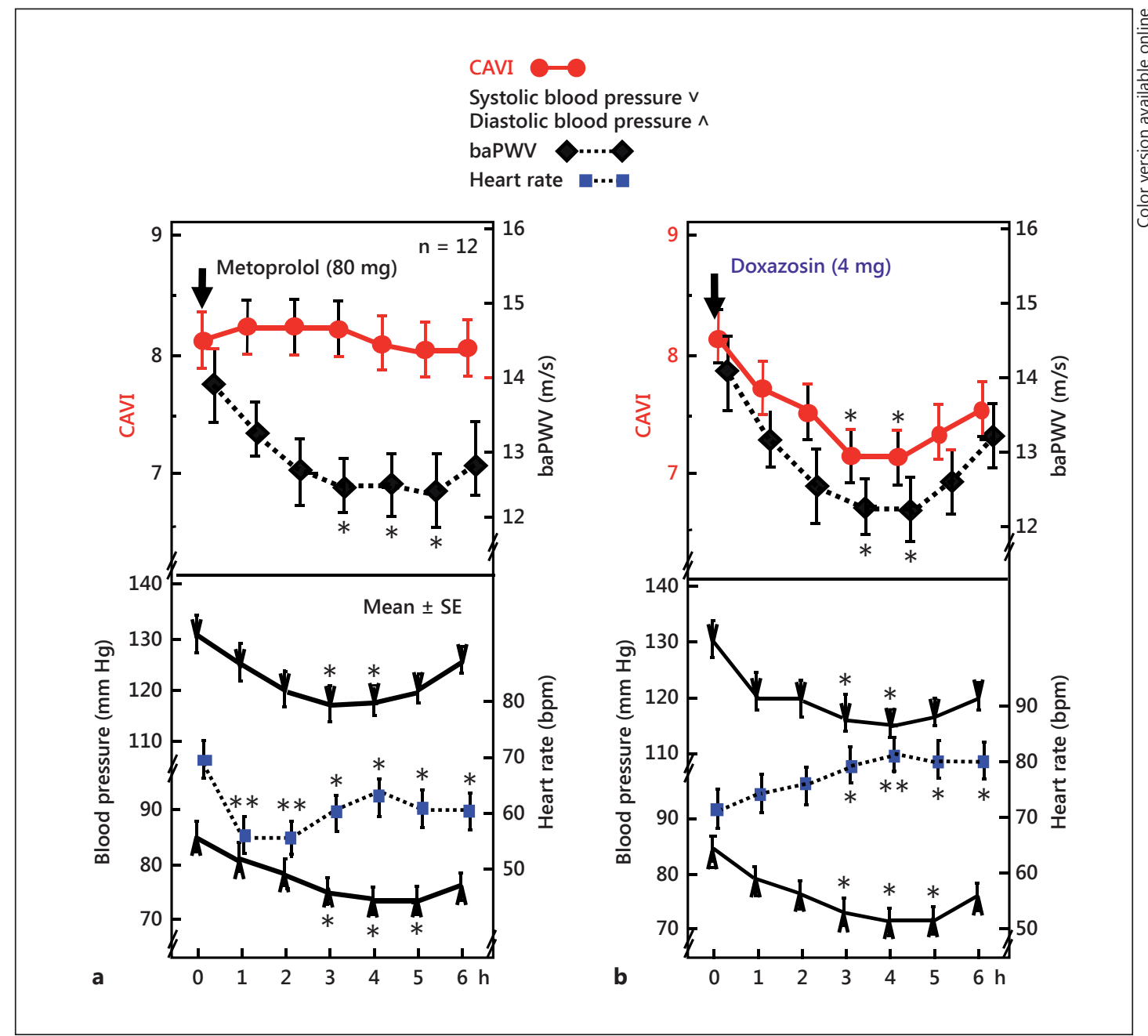

Fig. 2. Effects of the $\beta_{1}$-blocker metoprolol and $\alpha_{1}$-blocker doxazosin on CAVI and baPWV [16]. a When the selective $\beta_{1}$-adrenergic blocker metoprolol ( $80 \mathrm{mg}$ ) was administered, both systolic and diastolic blood pressures decreased and baPWV also decreased, but CAVI did not change. This study indicates that CAVI is independent of blood pressure at the time of measurement. b Furthermore, with the administration of the selective $\alpha_{1}$ adrenergic receptor blocker doxazosin ( $4 \mathrm{mg}$ ), systolic and diastolic blood pressures as well as CAVI and baPWV decreased, indicating that CAVI decreased with a relaxation of smooth muscles induced by the $\alpha_{1}$-adrenergic receptor blocker. ${ }^{*} \mathrm{p}<0.05,{ }^{* *} \mathrm{p}<0.01$ vs. baseline, Bonferroni test. Reproduced from Shirai et al. [16].

muscle cells, whereas baPWV decreases because PWV has the property to decrease according to a decrease in blood pressure [11]. This study indicated that CAVI was not influenced by blood pressure at the time of measurement. Therefore, CAVI can be used to measure the proper stiffness of the arterial wall ignoring the blood pressure change at a measuring time.

When the selective $\alpha_{1}$-blocker doxazosin, which decreases blood pressure by relaxing vascular smooth muscle tone, was administered to men, systolic and diastolic blood pressure decreased for 6 h. During this time, CAVI decreased (fig. 2b). This result indicated that CAVI was reflecting smooth muscle tone.

These results support the idea that CAVI reflects not only the organic stiffness of the arterial wall, but also the functional stiffness comprising the contracture of arterial smooth muscle cells controlled by vasoactive compounds such as catecholamine. 
Shirai et al.: The Role of Monitoring Arterial Stiffness with Cardio-Ankle Vascular Index in the Control of Lifestyle-Related Diseases

Fig. 3. Effects of age on CAVI. CAVI was measured in Japanese workers and their families. CAVI increased with age, and the values of CAVI were higher in men than women at any age. CAVI $=0.5$ by 10 years; men > women by 0.2 (= difference of 5 years). Modified from Namekata et al. [17].

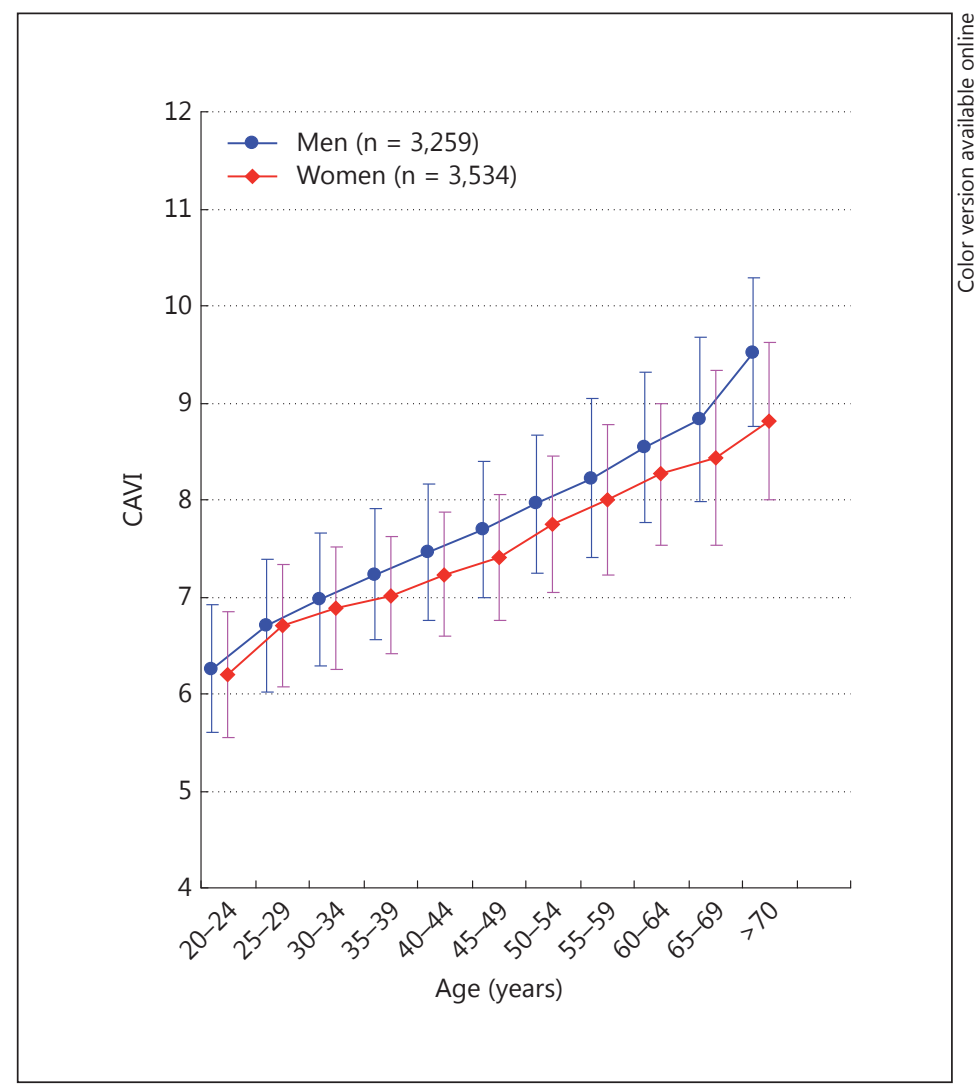

\section{CAVI as a Surrogate Marker of Arteriosclerotic Diseases}

\section{Aging}

CAVI of healthy people without cardiovascular risk factors increases with aging from 20 to 70 years, as shown in figure 3 [17]. CAVI of men is higher than that of women at all ages by a factor of nearly 0.2 .

Choi et al. [30] reported that CAVI is a sensitive marker of the arterial aging process, above and beyond conventional arm blood pressure in Korean people (CAVI $=5.0+0.048 \times$ age in men, $4.8+0.045 \times$ age in women).

\section{Coronary Artery Disease}

As for coronary artery disease (CAD), CAVI increases as the number of coronary vessels with stenosis ( $>75 \%)$ increases, as shown in figure 4 [19]. The cutoff point of CAVI for the presence of coronary stenosis was 8.91 among the patients with a suspicion of ischemic CAD. Izuhara et al. [20] also reported the multiple logistic analysis revealing that CAVI, but not baPWV, was associated with the presence of carotid and coronary arteriosclerosis. Several researchers reported that CAVI was high in patients with CAD [31-33]. Yingchoncharoen et al. [34] reported that the traditional risk score (RAMA-EGAT) has been shown to be an accurate scoring system for predicting CAD. Furthermore, they reported that the addition of CAVI to the RAMA-EGAT score significantly improves the diagnostic yield of CAD. Park et al. [35] also reported that the addition of CAVI $>8$ to traditional risk factors improved the predictive value for coronary stenosis. Park et al. [36] reported that CAVI was related to coronary artery calcification or stenosis in asymptomatic subjects in Korea. 
Shirai et al.: The Role of Monitoring Arterial Stiffness with Cardio-Ankle Vascular Index in the Control of Lifestyle-Related Diseases

Fig. 4. The relationship between the number of affected coronary arteries and CAVI. * $\mathrm{p}<0.05$; $* * \mathrm{p}<0.001$. Reproduced from Nakamura et al. [18].

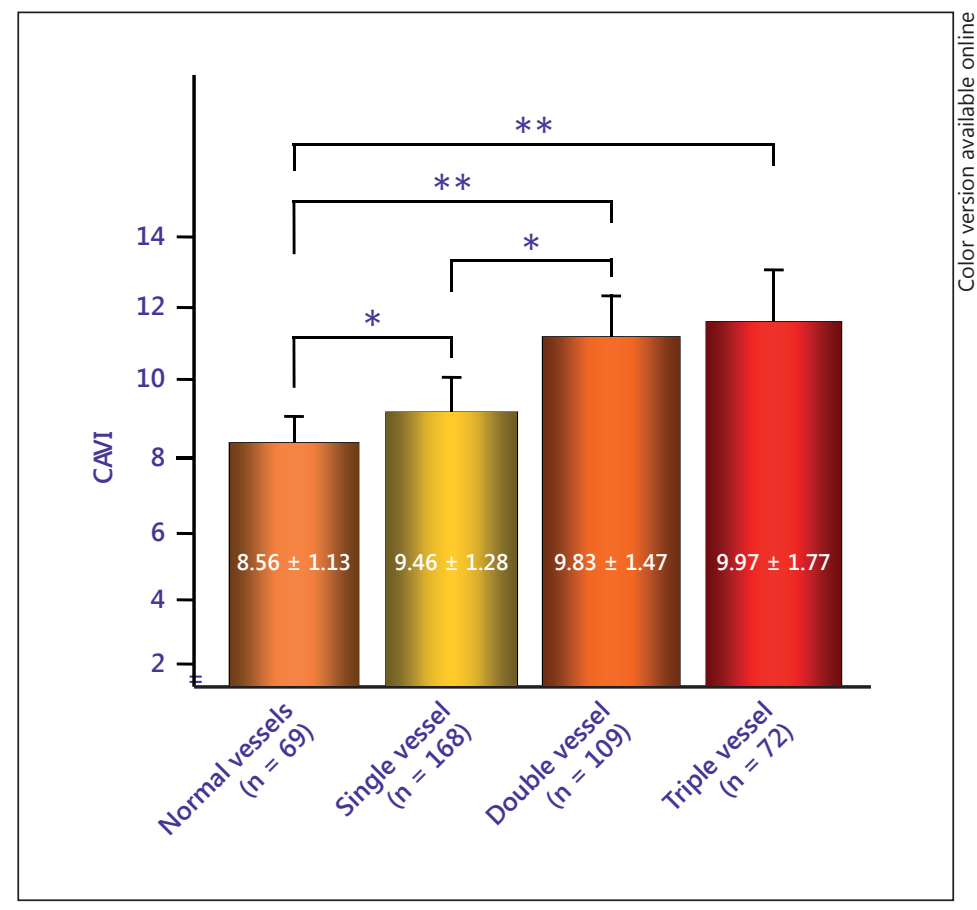

\section{Carotid Arteriosclerosis}

As for intima-media thickness (IMT) of the carotid artery, several researchers showed a strong correlation between CAVI and IMT, but plaque score showed a much more stronger correlation with CAVI $[37,38]$. Hu et al. [39] reported that CAVI $=8.0$ may be an optimal cutoff point for carotid arteriosclerosis prediction, and the older Chinese population with higher CAVI scores also had a higher risk of carotid arteriosclerosis.

\section{Chronic Kidney Disease}

As for chronic kidney disease, there have been several reports that CAVI correlated with estimated glomerular filtration rate [19, 40, 41]. The typical data from Nakamura et al. [19] are shown in figure 5. CAVI was also reported to be high in patients undergoing hemodialysis therapy [42].

\section{Cerebral Infarction}

Suzuki et al. [43] reported that CAVI was related to cerebrovascular accidents. Choi et al. [44] found that arterial stiffness assessed using CAVI reflects cerebral small vessel disease in healthy young and middle-aged subjects.

The above results indicated that most of the arteriosclerotic diseases showed high CAVI values. It is suggested that CAVI is a good indicator of systemic arteriosclerosis.

\section{CAVI of Coronary Risk Factors and Their Control}

\section{Diabetes Mellitus}

CAVI is reported to be high in patients with diabetes mellitus [21]. Kim et al. [45] reported that diabetic peripheral neuropathy was associated with increased CAVI without changes in carotid IMT in type 2 diabetes. Kim et al. [46] found that increased CAVI in T2DM patients is 
Fig. 5. Comparison of CAVI in estimated glomerular filtration rate (eGFR) quartiles. CAVI was negatively correlated with eGFR. CAVI might be a possible indicator of chronic kidney disease. ${ }^{*} \mathrm{p}<0.05$; $* * \mathrm{p}<0.001$. Reproduced from Nakamura et al. [19].
Shirai et al.: The Role of Monitoring Arterial Stiffness with Cardio-Ankle Vascular Index in the Control of Lifestyle-Related Diseases

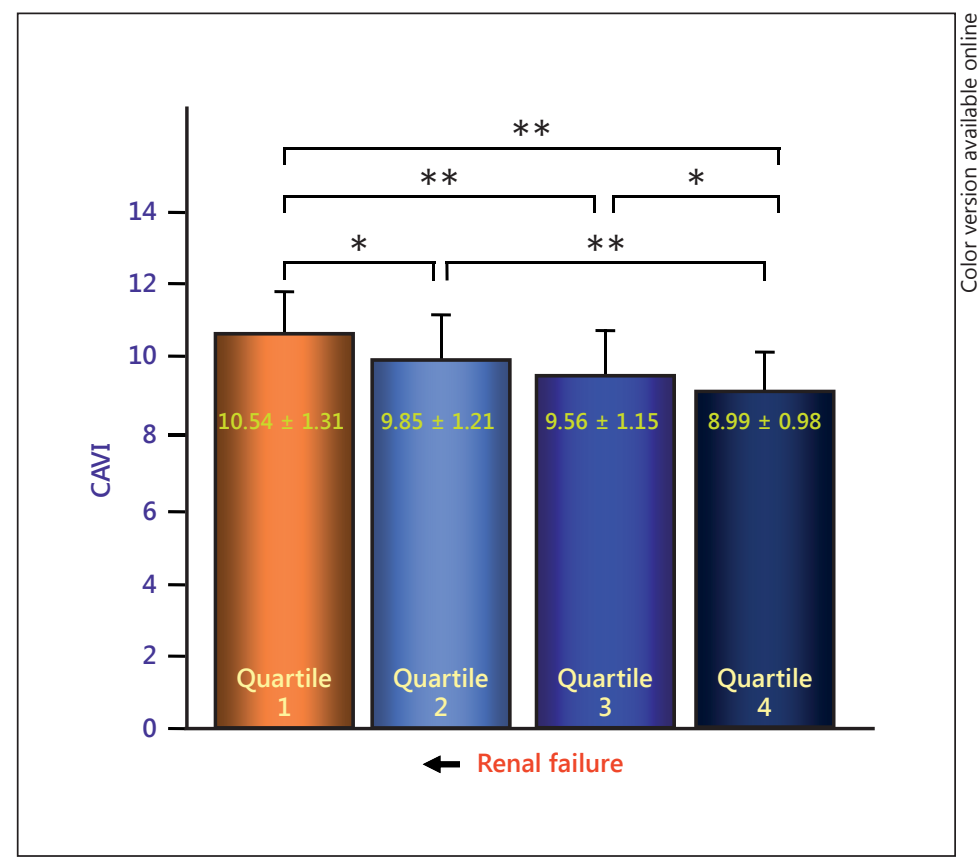

associated with the presence of arterial plaque, increased IMT and microvascular complication, such as nephropathy and neuropathy.

Glimepiride decreased CAVI accompanied with improved glucose level [26]. Insulin therapy also decreased CAVI accompanied with lowered blood glucose level [47]. These relatively short-term changes of CAVI by glucose control suggested that a high blood glucose level itself might increase the functional arterial stiffness by glucose toxication. However, the precise mechanism needs further study.

\section{Dyslipidemia}

CAVI may not be as closely related to hypercholesterolemia as to diabetes mellitus. Soska et al. [48] reported that CAVI was not necessarily high in heterozygous familial hypercholesterolemic patients. However, some reports showed that CAVI is related to LDL cholesterol level and also to the cholesterol/HDL cholesterol ratio [49]. Initial lipidosis induced by infiltration of LDL might soften the arterial wall. CAVI might increase following the occurrence of a complicated lesion. Cholesterol-lowering agents such as pitavastatin [50], ezetimibe [51] and the triglyceride-lowering agent eicosapentaenoic acid [52] have been reported to decrease CAVI.

\section{Hypertension}

Many papers reported that CAVI showed a high value in persons with hypertension [5355]. Several papers showed the effect of antihypertensive agents on CAVI. The decreasing rates of blood pressure by those agents are not necessarily correlated with the improvement rate of CAVI.

\section{Calcium Channel Blockers}

There are several types of calcium channel blockers (CCBs), such as L-channel blocker, T-channel blocker, and N-channel blocker. Amlodipine is known to be an L-channel blocker. Kurata et al. [56] reported that amlodipine decreased CAVI ( $\mathrm{n}=10,24$ weeks of treatment). Miyashita et al. [25] reported that the decrease by amlodipine was small and not significant. 
Shirai et al.: The Role of Monitoring Arterial Stiffness with Cardio-Ankle Vascular Index in the Control of Lifestyle-Related Diseases

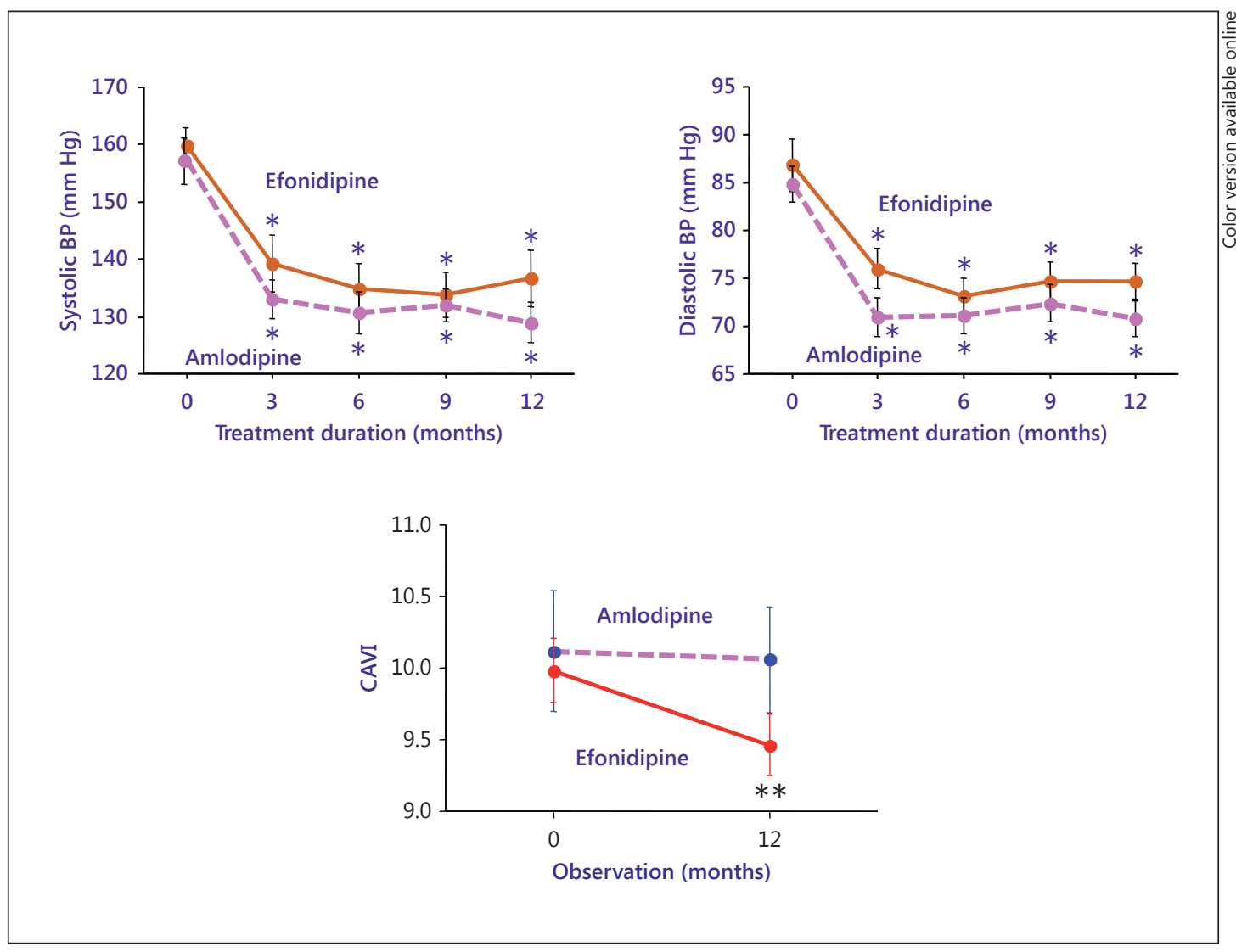

Fig. 6. Comparison between the effects of amlodipine and efonidipine on CAVI. Blood pressure (BP) decreased with both agents at almost the same rates, but the rate of decrease was different. Efonidipine decreased CAVI to a much greater extent than amlodipine. Reproduced from Sasaki et al. [57].

Sasaki et al. [57] compared the effects of efonidipine (T-channel blocker) and of amlodipine (L-channel blocker). The blood pressures were reduced by almost the same values (fig. 6). CAVI was significantly reduced by efonidipine but not by amlodipine. So, it is suggested that various types of Ca channel blockers had their own effects on arterial wall stiffness.

Angiotensin II Receptor Antagonists

As for angiotensin II receptor antagonists, there have been several reports. Olmesartan [26] and telmisartan [58] have been reported to decrease CAVI. In a comparison study between candesartan, telmisartan and losartan, Uehara and Takeda [59] noted that candesartan was best at reducing CAVI. Bukuda et al. [60] studied the effect of candesartan as compared with CCBs. They showed that blood pressure decreased significantly in both groups, and the rates were not different in both groups, but candesartan significantly reduced CAVI but not CCBs. Angiotensin II receptor antagonists might be better for improving CAVI, but further studies are required.

Thiazide

Diuretics are known to decrease blood pressure, but may exacerbate insulin resistance. The real effects of diuretics on arterial wall stiffness have not been studied. However, the combination of olmesartan and azelnidipine has advantages over the combination of olme- 
sartan and thiazide with respect to CAVI in patients with moderate hypertension [61]. This might suggest that azelnidipine improved CAVI, but thiazide did not change CAVI. A tablet combining losartan and hydrochlorothiazide has been found to decrease CAVI [62].

\section{Metabolic Syndrome and Obesity}

CAVI has been shown to be high in the metabolic syndrome [22]. Park et al. [63] reported that epicardial fat showed an independent association with CAVI, but not subcutaneous fat, using 256-slice multidetector coronary computed tomography.

Moreover, body weight loss improved CAVI in obese patients with the metabolic syndrome in addition to reducing risk factors [22]. CAVI was also improved by weight loss using formula $\operatorname{diet}[64]$.

\section{Smoking}

CAVI has been shown to be high in smokers and to decrease with smoking cessation [24]. Measuring CAVI might promote the motivation to stop smoking.

\section{Sleep Apnea Syndrome}

CAVI has been reported to be elevated in the patients with sleep apnea syndrome (SAS) [65] and decreased by continuous positive airway pressure treatment [66]. These results obtained by CAVI suggested strongly that SAS worked as a stress factor for the arterial wall, and that SAS might promote systemic arteriosclerosis.

Uric Acid

Uric acid as a risk factor for arteriosclerosis is controversial because uric acid is known to have both antioxidant [67] and pro-oxidative action in the process of production [68]. Nagayama et al. [69] have recently reported that CAVI increased progressively with increasing serum uric acid tertile after adjusting for age, BMI and systolic blood pressure in multiple regression analysis. Li et al. [70] also documented that uric acid increased arterial stiffness measured by CAVI.

Inflammatory Arterial Disease: Systemic Lupus Erythematosus

Saito et al. [71] reported that CAVI was higher in both premenopausal and postmenopausal systemic lupus erythematosus patients.

\section{Mental Stress}

Shimizu et al. [72] reported that people who experienced a huge earthquake had hardened arterial stiffness, indicating that mental stress also increases CAVI (fig. 7).

The above-mentioned results are listed in figure 8 . CAVI was increased by various arteriosclerotic diseases and also by most of the risk factors. Furthermore, CAVI improved with most of the adequate treatments for those risk factors.

\section{CAVI as a Predictor of Cardiovascular Events}

There are a few reports dealing with the relationship between prognosis and CAVI. Kubota et al. [73] reported that the group with a CAVI >10 showed a high incidence of heart diseases and cerebrovascular accidents in 3 years. CAVI was found to be associated with future renal dysfunction, thus suggesting that a CAVI $>10$ may be a risk factor for chronic kidney disease in Japanese patients [74]. Kato et al. [75] reported that baPWV is superior to CAVI as a predictor of cardiovascular outcomes in patients on chronic hemodialysis. 
Fig. 7. Changes in CAVI following the huge East Japan earthquake in hypertensive patients who lived $250 \mathrm{~km}$ away from the epicenter. Data are presented as mean \pm SD. ${ }^{*} \mathrm{p}<0.05 ;{ }^{* * *} \mathrm{p}<0.0001$.
Shirai et al.: The Role of Monitoring Arterial Stiffness with Cardio-Ankle Vascular Index in the Control of Lifestyle-Related Diseases

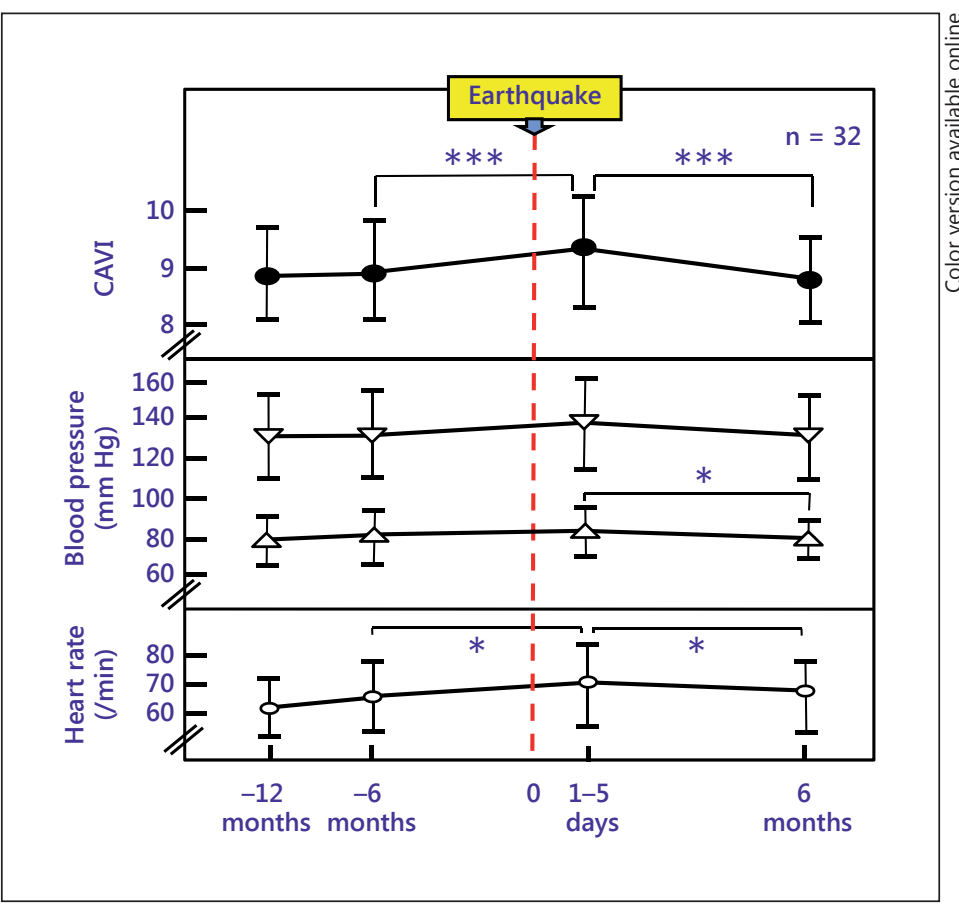

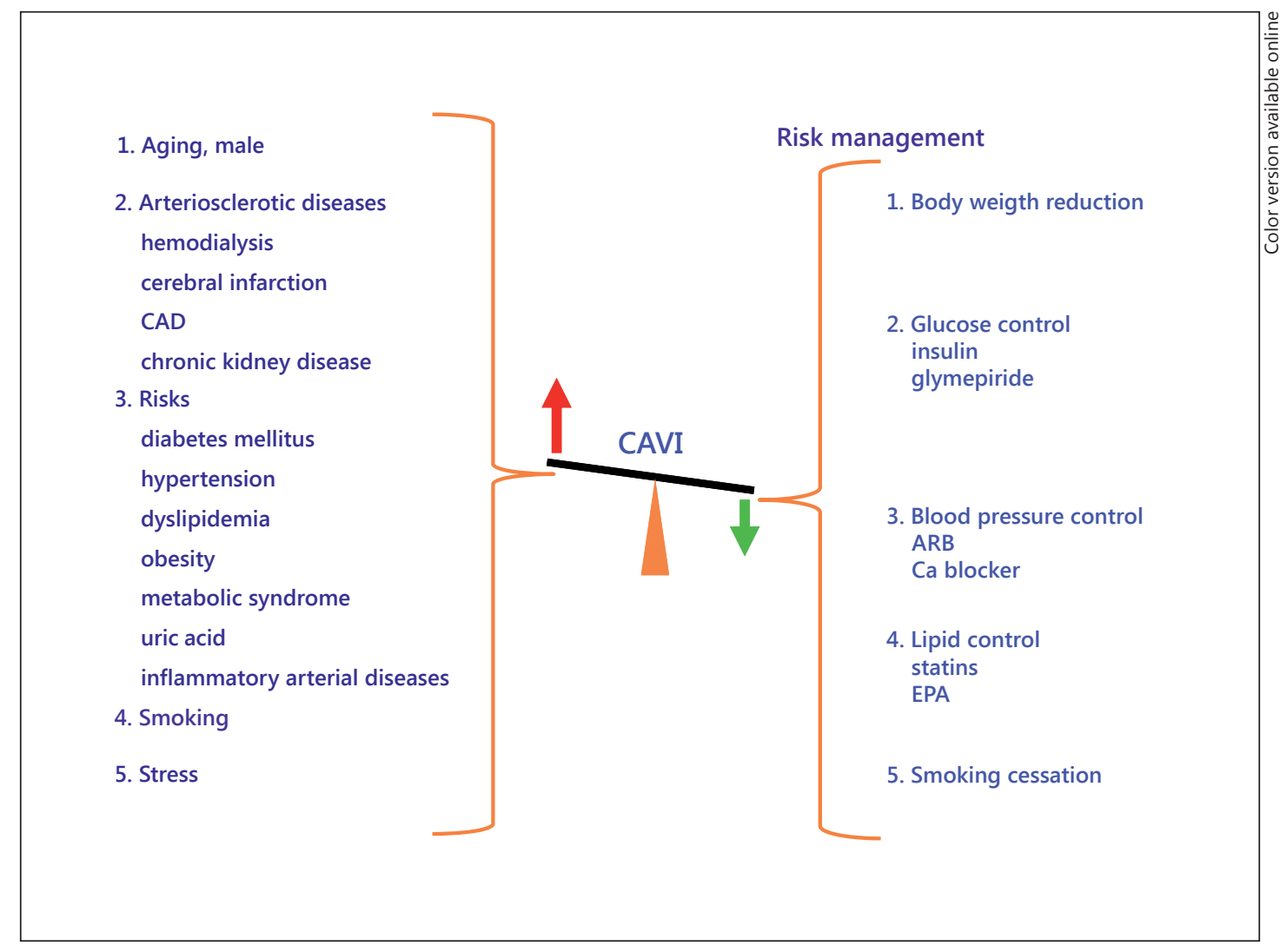

Fig. 8. CAVI in arteriosclerotic diseases and coronary risk factors. CAVI showed high value in typical arteriosclerotic diseases and also in persons with cardiovascular risk factors. Also, CAVI decreased with improvement of those risk factors. EPA = Eicosapentaenoic acid. 


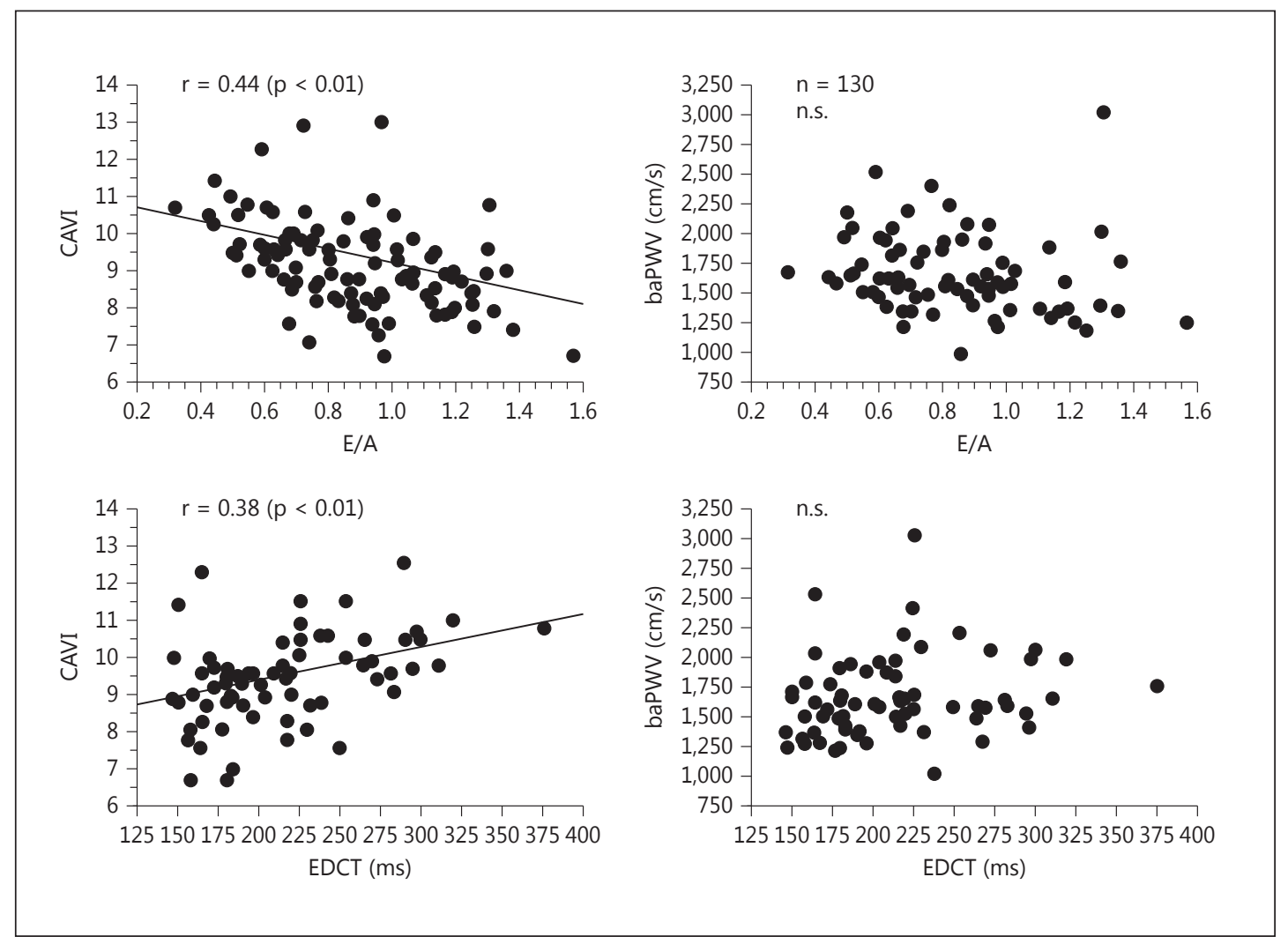

Fig. 9. The correlation of CAVI and baPWV with E/A and deceleration time of the E wave (EDCT) in patients with chest pain syndrome who underwent coronary angiography. Reproduced from Takaki et al. [79].

These results need to be detailed in a further study. Otsuka et al. [76] reported that persistently impaired CAVI was an independent predictor of future cardiovascular disease events.

\section{CAVI as an Indicator of Vascular Function}

Blood stasis syndrome is defined as retardation or cessation of the blood flow and is regarded as the cause or product of many chronic diseases in traditional Asian medicine. Cho et al. [77] reported that CAVI combined with age can clinically serve as an objective tool to diagnose blood stasis syndrome in stroke patients. Shiba et al. [78] reported that the optic nerve head circulation was significantly correlated with CAVI. This suggests that microcirculation is determined by arterial stiffness.

Takaki et al. [79] investigated the heart function in angina pectoris patients, in particular the relationship between left ventricular diastolic function and CAVI. They studied CAVI and the peak velocities of early and late mitral inflow ( $E$ and $A$, respectively) and obtained results showing that the E/A ratio negatively correlated with CAVI and that the deceleration time of the E wave positively correlated with CAVI (fig. 9).

Zhang et al. [28] measured CAVI during the therapy of congestive heart failure patients. CAVI decreased during the therapy, and the improvement of heart functions such as the ejection fraction strongly correlated with CAVI (table 1). Schillaci et al. [29] evaluated the 
Fig. 10. The meaning of CAVI. CAVI reflects the proper arterial stiffness, which is a surrogate marker of arteriosclerosis, but is also involved in the interrelationship with left ventricular function as a windkessel. $\Delta \mathrm{D}=$ Change in diameter; $\mathrm{D}=$ diameter of the vessel.

Table 1. Contributing factors in improvement of left ventricular ejection fraction during treatment of heart failure $(\mathrm{n}=30)$
Shirai et al.: The Role of Monitoring Arterial Stiffness with Cardio-Ankle Vascular Index in the Control of Lifestyle-Related Diseases

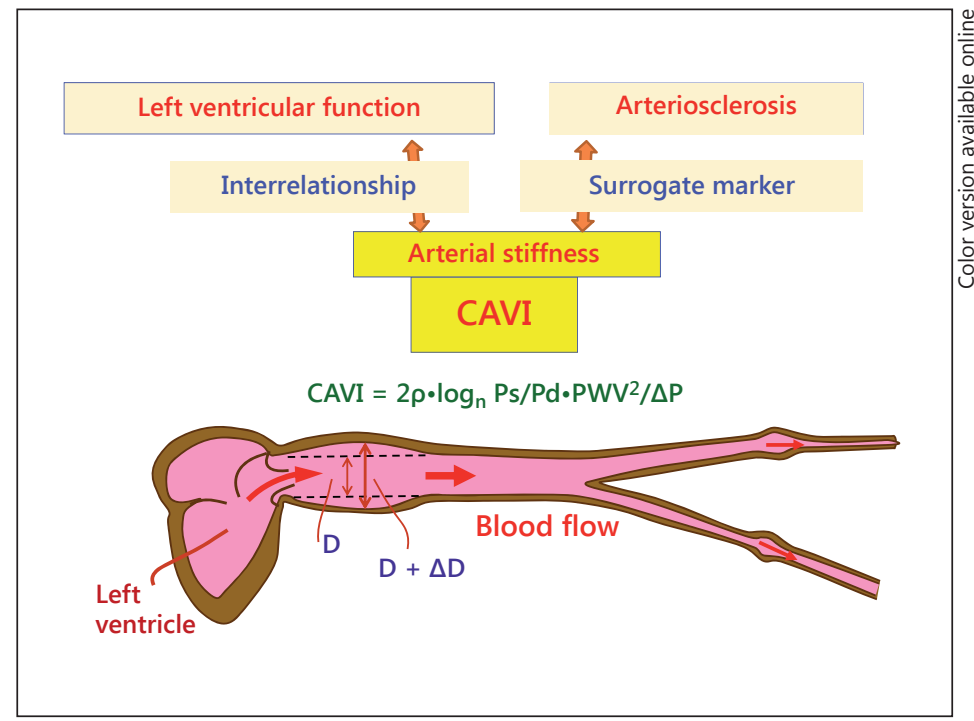

\begin{tabular}{lll}
\hline & Correlation coefficient, $r$ & $\mathrm{p}$ value \\
\hline$\Delta$ systolic BP & 0.0204 & n.s. \\
$\Delta$ diastolic BP & -0.1100 & n.s. \\
$\Delta$ CAVI & -0.3272 & $<0.05$ \\
$\Delta$ CTR & $-1,799$ & n.s. \\
$\Delta$ E /é & -0.2445 & n.s. \\
$\Delta$ BNP & -0.0204 & n.s. \\
\hline
\end{tabular}

Data are presented as mean $\pm \mathrm{SD}$. $\mathrm{BP}=$ Blood pressure; $\mathrm{CTR}=$ cardiothoracic ratio; $\mathrm{E} / \mathrm{e}=\mathrm{E}$ velocity/é velocity; $\mathrm{BNP}=$ brain natriuretic peptide; n.s. = not significant.

relationship between CAVI and left ventricular structure and systolic function in hypertensive patients, and reported that CAVI may have a relation to left ventricular structure and function that is independent of blood pressure levels.

These results suggest that there is a relationship between left ventricular function and vascular function by which blood from the heart is smoothly and efficiently transported to peripheral organs. CAVI might be a useful indicator of this vascular function. It could also be mentioned that vascular function as measured with CAVI is related to peripheral circulation.

\section{Conclusion}

CAVI reflects the degree of arteriosclerosis (organic stiffness) and also the contracture of smooth muscle cells (functional stiffness) (fig. 10). CAVI is recommended to be measured in patients with lifestyle-related diseases every 3-4 months in routine clinical practice for evaluation of adequate risk factor control. Furthermore, CAVI reflects vascular function in relating to left ventricular function. This might contribute to a new field of vascular function. 
Shirai et al:: The Role of Monitoring Arterial Stiffness with Cardio-Ankle Vascular Index in the Control of Lifestyle-Related Diseases

\section{Acknowledgements}

We are very grateful to the doctors in the Department of Internal Medicine and the staff of Functional Physiological Division in Sakura Hospital, Toho University, for their cooperation in conducting research on CAVI. We are also grateful to the staff of Mihama Hospital for measuring CAVI over many years.

\section{Disclosure Statement}

The authors declare no conflict of interest.

\section{References}

1 World Health Organization: The World Health Report 2001 Annex Table 2. Deaths by Causes, Sex and Mortality Stratum in WHO Regions, Estimates for 2000. Geneva, World Health Organization, 2001. http://www.who. int/whr/2001/main/en/annex/annex2.htm (accessed May 8, 2002).

-2 Murray CJ, Lopez AD: Alternative projections of mortality and disability by cause 1990-2020: Global Burden of Disease Study. Lancet 1997;349:1498-1504.

3 Asmar R: Pulse wave velocity principles and measurement; in Asmar R, O’Rourke MF, Safar M (eds): Arterial Stiffness and Pulse Wave Velocity. Amsterdam, Elsevier, 1999, pp 25-55.

4 Oliver JJ, Webb DJ: Noninvasive assessment of arterial stiffness and risk of atherosclerotic events. Arterioscler Thromb Vasc Biol 2003;23:554-566.

-5 Mattace-Raso FU, van der Cammen TJ, Hofman A, van Popele NM, Bos ML, Schalekamp MA, Asmar R, Reneman RS, Hoeks AP, Breteler MM, Witteman JC: Arterial stiffness and risk of coronary heart disease and stroke: the Rotterdam Study. Circulation 2006;113:657-663.

-6 O'Rourke MF, Staessen JA, Vlachopoulos C, Duprez D, Plante GE: Clinical applications of arterial stiffness; definitions and reference values. Am J Hypertens 2002;15:426-444.

7 Hasegawa M: Fundamental research on human aortic pulse wave velocity. Jikei Med J 1970;85:742-760.

-8 Yamashina A, Tomiyama H, Takeda K, Tsuda H, Arai T, Koji Y, Hori S, Yamamoto Y: Validity, reproducibility, and clinical significance of noninvasive brachial-ankle pulse wave velocity measurement. Hypertens Res 2002;25:359-364.

-9 Kim HJ, Nam JS, Park JS, Cho M, Kim CS, Ahn CW, Kwon HM, Hong BK, Yoon YW, Cha BS, Kim KR, Lee HC: Usefulness of brachial-ankle pulse wave velocity as a predictive marker of multiple coronary artery occlusive disease in Korean type 2 diabetes patients. Diabetes Res Clin Pract 2009;85:30-34.

10 Laurent S, Boutouyrie P, Asmar R, Gautier I, Laloux B, Guize L, et al: Aortic stiffness is an independent predictor of all-cause and cardiovascular mortality in hypertensive patients. Hypertension 2001;37:1236-1241.

11 Nye ER: The effect of blood pressure alteration on the pulse wave velocity. Br Heart J 1964;266:261-265.

$\checkmark 12$ Shirai K, Utino J, Otsuka K, Takata M: A novel blood pressure-independent arterial wall stiffness parameter; cardio-ankle vascular index (CAVI). J Atheroscler Thromb 2006;13:101-107.

13 Hayashi K, Handa H, Nagasawa S, Okumura A, Moritake K: Stiffness and elastic behavior of human intracranial and extracranial arteries. J Biomech 1980;13:175-184.

14 Kawasaki T, Sasayama S, Yagi S: Noninvasive assessment of the age related changes in stiffness of major branches of the human arteries. Cardiovasc Res 1987;21:678-687.

15 Bramwell JC, Hill AV: Velocity of the pulse wave in man. Proc Biol Sci 1922;93:298-306.

16 Shirai K, Song M, Suzuki J, Kurosu T, Oyama T, Nagayama D, Miyashita Y, Yamamura S, Takahashi M: Contradictory effects of $\beta_{1}$ - and $\alpha_{1}$-aderenergic receptor blockers on cardio-ankle vascular stiffness index (CAVI) the independency of CAVI from blood pressure. J Atheroscler Thromb 2011;18:49-55.

17 Namekata T, Suzuki K, Ishizuka N, Shirai K: Establishing baseline criteria of cardio-ankle vascular index as a new indicator of arteriosclerosis: a cross-sectional study. BMC Cardiovasc Disord 2011;11:51.

-18 Nakamura K, Tomaru T, Yamamura S, Miyashita Y, Shirai K, Noike H: Ankle vascular index is a candidate predictor of coronary atherosclerosis. Circ J 2008;72:598-604.

19 Nakamura K, Iiduka T, Takahashi M, Shimizu S, Mikamo H, Nakagami T, Suzuki M, Hirano K, Sugiyama Y, Tomaru T, Miyashita Y, Shirai K, Noike H: Association between cardio-ankle vascular index and serum cystatin C levels in patients with cardiovascular risk factor. J Atheroscler Thromb 2009;16:371-379.

20 Izuhara M, Shioji K, Kadota Y, Baba O, Takeuchi Y, Uegaito T, Mutsuo S, Matsuda M: Relationship of cardiovascular index to carotid and coronary arteriosclerosis. Circ J 2008;72:1762-1767.

21 Ibata J, Sasaki H, Kakimoto T, Matsuno S, Nakatani M, Kobayashi M, et al: Cardio-ankle vascular index measures arterial wall stiffness independent of blood pressure. Diabetes Res Clin Pract 2008;80:265-270.

22 Satoh N, Shimatsu A, Kato Y, Araki K, Koyama K, Okajima T, Tanabe M, Ooishi M, Kotani K, Ogawa Y: Evaluation of the cardio-ankle vascular index, a new indicator of arterial stiffness independent of blood pressure, in obese and metabolic syndrome. Hypertens Res 2008;31:1921-1930. 
Shirai et al.: The Role of Monitoring Arterial Stiffness with Cardio-Ankle Vascular Index in the Control of Lifestyle-Related Diseases

-23 Okura T, Watanabe S, Kurata M, Manabe S, Koresawa M, Irita J, et al: Relationship between cardio-ankle vascular index (CAVI) and carotid atherosclerosis in patients with essential hypertension. Hypertens Res 2007;30:335-340.

24 Noike H, Nakamura K, Sugiyama Y, Iizuka T, Shimizu K, Takahashi M, Hirano K, Suzuki M, Mikamo H, Nakagami T, Shirai K: Changes in cardio-ankle vascular index in smoking cessation. J Atheroscler Thromb 2010;17:517525.

25 Miyashita Y, Saiki A, Endo K, Ban N, Yamaguchi T, Kawana H, et al: Effects of olmesartan, an angiotensin II receptor blocker, and amlodipine, a calcium channel blocker, on Cardio-Ankle Vascular Index (CAVI) in type 2 diabetic patients with hypertension. J Atheroscler Tromb 2009;16:621-626.

26 Nagayama D, Saiki A, Endo K, Yamaguchi T, Ban N, Kawana H, et al: Improvement of cardio-vascular vascular index by glimepiride in type 2 diabetic patients. Int J Clin Pract 2010;64:1796-1801.

27 Miyashita Y, Endo K, Saiki A, Ban N, Yamaguchi T, Kawana H, et al: Effects of pitavastatin, a 3-hydroxy-3-methylglutaryl coenzyme a reductase inhibitor, on cardio-ankle vascular index in type 2 diabetic patients. J Atheroscler Thromb 2009;16:539-545.

28 Zhang C, Ohira M, Iizuka T, Mikamo H, Nakagami T, Suzuki M, et al: Cardio-ankle vascular index relates to left ventricular ejection fraction in patients with heart failure. A retrospective study. Int Heart J 2013;54:216-221.

29 Schillaci G, Battista F, Settimi L, Anastasio F, Pucci G: Cardio-ankle vascular index and subclinical heart disease. Hypertens Res 2015;38:68-73.

-30 Choi SY, Oh BH, Park JB, Choi DJ, Rhee MY, Park S: Age-associated increase in arterial stiffness measured according to the cardio-ankle vascular index without blood pressure changes in healthy adults. J Atheroscler Thromb 2013;20:911-923.

-31 Miyoshi T, Doi M, Hirohata S, Sakane K, Kamikawa S, Kitawaki T, Kaji Y, Kusano KF, Ninomiya Y, Kusachi S: Cardio-ankle vascular index is independently associated with the severity of coronary atherosclerosis and left ventricular function in patients with ischemic heart disease. J Atheroscler Thromb 2010;17:249-258.

32 Horinaka S, Yabe A, Yagi H, Ishimura K, Hara H, Iemura T, Matsuoka H: Comparison of atherosclerotic indicators between cardio ankle vascular index and brachial ankle pulse wave velocity. Angiology 2009;60:468476.

33 Sairaku A, Eno S, Hondo T, Teragawa H, Nakano Y, Matsuda K, Kisaka T, Kihara Y: Head-to-head comparison of the cardio-ankle vascular index between patients with acute coronary syndrome and stable angina pectoris. Hypertens Res 2010;33:1162-1166.

-34 Yingchoncharoen T, Limpijankit T, Jongjirasiri S, Laothamatas J, Yamwong S, Sritara P: Arterial stiffness contributes to coronary artery disease risk prediction beyond the traditional risk score (RAMA-EGAT score). Heart Asia 2012;4:77-82.

-35 Park HE, Choi SY, Kim MK, Oh BH: Cardio-ankle vascular index reflects coronary atherosclerosis in patients with abnormal glucose metabolism: assessment with 256 slice multi-detector computed tomography. J Cardiol 2012;60:372-376.

-36 Park JB, Park HE, Choi SY, Kim MK, Oh BH: Relation between cardio-ankle vascular index and coronary artery calcification or stenosis in asymptomatic subjects. J Atheroscler Thromb 2013;20:557-567.

37 Izuhara M, Shioji K, Kadota Y, Baba O, Takeuchi Y, Uegaito T, et al: Relationship of cardio-vascular index (CAVI) to carotid and coronary arteriosclerosis. Circ J 2008;72:1762-1767.

-38 Okura T, Watanabe S, Kurata M, Manabe S, Koresawa M, Irita J, et al: Relationship between cardio-ankle vascular index (CAVI) and carotid atherosclerosis in patients with essential hypertension. Hypertens Res 2007;30:335-340.

39 Hu H, Cui H, Han W, Ye L, Qiu W, Yang H, Zhang C, Guo X, Mao G: A cutoff point for arterial stiffness using the cardio-ankle vascular index based on carotid arteriosclerosis. Hypertens Res 2013;36:334-341.

40 Kubozono T, Miyata M, Ueyama K, Nagaki A, Hamasaki S, Kusano K, Kubozono O, Tei C: Association between arterial stiffness and estimated glomerular filtration rate in the Japanese general population. J Atheroscler Thromb 2009;16:840-845.

41 Ueyama K, Miyata M, Kubozono T, Nagaki A, Hamasaki S, Ueyama S, Tei C: Noninvasive indices of arterial stiffness in hemodialysis patients. Hypertens Res 2009;32:716-720.

42 Ichihara A, Yamashita N, Takemitsu T, Kaneshiro Y, Sakoda M, Kurauchi-Mito A, Itoh H: Cardio-ankle vascular index and ankle pulse wave velocity as a marker of arterial fibrosis in kidney failure treated by hemodialysis. Am J Kidney Dis 2008;52:947-955.

-43 Suzuki J, Sakakibara R, Tomaru T, Tateno F, Kishi M, Ogawa E, Kurosu T, Shirai K: Stroke and cardio-ankle vascular stiffness index. J Stroke Cerebrovasc Dis 2013;22:171-175.

44 Choi SY, Park HE, Seo H, Kim M, Cho SH, Oh BH: Arterial stiffness using cardio-ankle vascular index reflects cerebral small vessel disease in healthy young and middle aged subjects. J Atheroscler Thromb 2013;20:178185.

-45 Kim ES, Moon SD, Kim HS, Lim DJ, Cho JH, Kwon HS, Ahn CW, Yoon KH, Kang MI, Cha BY, Son HY: Diabetic peripheral neuropathy is associated with increased arterial stiffness without changes in carotid intima-media thickness in type 2 diabetes. Diabetes Care 2011;34:1403-1405.

-46 Kim KJ, Lee BW, Kim HM, Shin JY, Kang ES, Cha BS, Lee EJ, Lim SK, Lee HC: Associations between cardio-ankle vascular index and microvascular complications in type 2 diabetes mellitus patients. J Atheroscler Thromb 2011;18:328-836. 
Shirai et al.: The Role of Monitoring Arterial Stiffness with Cardio-Ankle Vascular Index in the Control of Lifestyle-Related Diseases

47 Ohira M, Endo K, Oyama T, Yamaguchi T, Ban N, Kawana H, Nagayama D, Nagumo A, Saiki A, Murano T, Watanabe H, Miyashita Y, Shirai K: Improvement of postprandial hyperglycemia and arterial stiffness upon switching from premixed human insulin 30/70 to biphasic insulin aspart 30/70. Metabolism 2011;60:78-85.

-48 Soska V, Dobsak P, Dusek L, Shirai K, Jarkovsky J, Novakova M, Brhel P, Stastna J, Fajkusova L, Freiberger T, Yambe T: Cardio-ankle vascular index in heterozygous familial hypercholesterolemia. J Atheroscler Thromb 2012;19:453-461.

49 Satoh N, Shimatsu A, Kato Y, Araki K, Koyama K, Okajima T, et al: Evaluation of the cardio-ankle vascular index, a new indicator of arterial stiffness independent of blood pressure, in obese and metabolic syndrome. Hypertens Res 2008;31:1921-1930.

50 Miyashita Y, Endo K, Saiki A, Ban N, Yamaguchi T, Kawana H, Nagayama D, Ohira M, Oyama T, Shirai K: Effects of pitavastatin, a 3-hydroxy-3-methylglutaryl coenzyme a reductase inhibitor, on cardio-ankle vascular index in type 2 diabetic patients. J Atheroscler Thromb 2009;16:539-545.

51 Miyashita Y, Endo K, Saiki A, Ban N, Nagumo A, Yamaguchi T, Kawana H, Nagayama D, Ohira M, Oyama T, Shirai K: Effect of ezetimibe monotherapy on lipid metabolism and arterial patients. J Atheroscler Thromb 2010;17: 1070-1076.

-52 Satoh N, Shimatsu A, Kotani K, Himeno A, Majima T, Yamada K, Suganami T, Ogawa Y: Highly purified eicosapentaenoic acid reduces cardio-ankle vascular index in association with decreased serum amyloid A-LDL in metabolic syndrome. Hypertens Res 2009;32:1004-1008.

53 Namekata T, Suzuki K, Ishizuka N, Nakata M, Shirai K: Association of cardio-ankle vascular index with cardiovascular disease risk factors and coronary heart disease among Japanese urban workers and their families. J Clin Exp Cardiol 2012;S1-003.

54 Okura T, Watanabe S, Kurata M, Manabe S, Koresawa M, Irita J, et al: Relationship between cardio-ankle vascular index (CAVI) and carotid atherosclerosis in patients with essential hypertension. Hypertens Res 2007;30:335-340.

55 Takaki A, Ogawa H, Wakeyama T, Iwami T, Kimura M, Hadano Y, et al: Cardio-ankle vascular index is superior to brachial-ankle pulse wave velocity as an index of arterial stiffness. Hypertens Res 2008;31:1347-1355.

56 Kurata M, Okura T, Watanabe S, Enomoto D, Johtoku M, Miyoshi K, Koresawa M, Fukuoka T, Higaki J: Effects of amlodipine and candesartan on arterial stiffness estimated by cardio-ankle vascular index in patients with essential hypertension: a 24-week study. Curr Ther Res 2008;69:412-422.

-57 Sasaki H, Saiki A, Endo K, Ban N, Yamaguchi T, Kawana H, Nagayama D, Ohhira M, Oyama T, Miyashita Y, Shirai K: Protective effects of efonidipine, a T- and L-type calcium channel blocker, on renal function and arterial stiffness in type 2 diabetic patients with hypertension and nephropathy. J Atheroscler Thromb 2009;16:568575.

58 Kinouchi K, Ichihara A, Sakoda M, Kurauchi-Mito A, Murohashi-Bokuda K, Itoh H: Effects of telmisartan on arterial stiffness assessed by the cardio-ankle vascular index in hypertensive patients. Kidney Blood Press Res 2010;33:304-312.

-59 Uehara G, Takeda H: Relative effects of telmisartan, candesartan and losartan on alleviating arterial stiffness in patients with hypertension complicated by diabetes mellitus: an evaluation using the cardiovascular index. J Intern Med Res 2008;36:1094-1102.

60 Bokuda K, Ichihara A, Sakoda M, Mito A, Kinouchi K, Itoh H: Blood pressure-independent effect of candesartan on cardio-ankle vascular index in hypertensive patients with metabolic syndrome. Vasc Health Risk Manag 2010;6:571-578.

-61 Ishimitsu T, Numabe A, Masuda T, Akabane T, Okamura A, Minami J, Matsuoka H: Angiotensin-II receptor antagonist combined with calcium channel blocker or diuretic for essential hypertension. Hypertens Res 2009;32:962-968.

62 Kinouchi K, Ichihara A, Sakoda M, Kurauchi-Mito A, Itoh H: Safety and benefits of a tablet combining losartan and hydrochlorothiazide in Japanese diabetic patients with hypertension. Hypertens Res 2009;32:11431147.

63 Park HE, Choi SY, Kim HS, Kim MK, Cho SH, Oh BH: Epicardial fat reflects arterial stiffness: assessment using 256-slice multidetector coronary computed tomography and cardio-ankle vascular index. J Atheroscler Thromb 2012;19:570-576.

64 Nagayama D, Endo K, Ohira M, Yamaguchi T, Nagumo A, Saiki A, et al: Effects of body weight reduction on cardio-ankle vascular index (CAVI). Obes Res Clin Pract 2011;7:e139-e145.

65 Kumagai T, Kasai T, Kato M, Naito R, Maeno K, Kasagi S, Kawana F, Ishiwata S, Narui K: Establishment of the cardio-ankle vascular index in patients with obstructive sleep apnea. Chest 2009;136:779-786.

-66 Kasai T, Inoue K, Kumagai T, Kato M, Kawana F, Sagara M, Ishiwata S, Ohno M, Yamaguchi T, Momomura S, Narui K: Plasma pentraxin3 and arterial stiffness in men with obstructive sleep apnea. Am J Hypertens 2011; 24:401-407.

67 Kang DH, Ha SK: Uric acid puzzle: dual role as anti-oxidant and pro-oxidant. Electrolyte Blood Press 2014;12: $1-6$.

68 Niskanen LK, Laaksonen DE, Nyyssonen K, et al: Uric acid level as a risk factor for cardiovascular and all-cause mortality in middle-aged men: a prospective cohort study. Arch Intern Med 2004;164:1546-1551.

69 Nagayama D, Yamaguchi T, Saiki A, Imamura H, Sato Y, Ban N, Kawana H, Nagumo A, Shirai K, Tatsuno I: High serum uric acid is associated with increased cardio-ankle vascular index (CAVI) in healthy Japanese subjects: a cross-sectional study. Atherosclerosis 2015;239:163-168. 
70 Li Y, Lu J, Wu X, Yang C: Serum uric acid concentration and asymptomatic hyperuricemia with subclinical organ damage in general population. Angiology 2013;65:634-640.

71 Saito H, Miida T, Wada Y, Maruyama M, Murakami S, Hasegawa H, Kuroda T, Narita I, Nakano M, Gejyo F: Atherosclerosis is accelerated in patients with long-term well-controlled systemic lupus erythematosus (SLE). Clin Chim Acta 2007;385:35-42.

-72 Shimizu K, Takahashi M, Shirai K: A huge earthquake hardened arterial stiffness monitored with cardio-ankle vascular index. J Atheroscler Thromb 2013;20:503-511.

73 Kubota Y, Maebuchim D, Takei M, Inui Y, Sudo Y, Ikegami Y, et al: Cardio-ankle vascular index is a predictor of cardiovascular events. Artery Res 2011;5:91-96.

74 Maebuchi D, Sakamoto M, Fuse J, Tanaka H, Shiraishi Y, Takei M, Inui Y, Sutoh Y, Ikegami Y, Momiyama Y: The cardio-ankle vascular index predicts chronic kidney disease in Japanese subjects. Artery Res 2013;7:48e53.

75 Kato A, Takita T, Furuhashi M, Maruyama Y, Miyajima H, Kumagai H: Brachial-ankle pulse wave velocity and the cardio-ankle vascular index as a predictor of cardiovascular outcomes in patients on regular hemodialysis. Ther Apher Dial 2012;16:232-241.

76 Otsuka T, Fukuda S, Shimada K, Suzoshikawa J: Serial assessment of arterial stiffness by cardio-ankle vascular index for prediction of future cardiovascular events in patients with coronary artery disease. Hypertens Res 2014;37:1014-1020.

-77 Cho K-H, Kim K-P, Woo B-C, Kim Y-J, Park J-Y, Cho S-Y, Park S-U, Jung W-S, Park J-M, Moon S-K: Relationship between blood stasis syndrome score and cardioankle vascular index in stroke patients. Evid Based Complement Alternat Med 2012;2012:696983.

78 Shiba T, Takahashi M, Hori Y, Maeno T: Optic nerve head circulation determined by pulse wave analysis is significantly correlated with cardio ankle vascular index, left ventricular diastolic function, and age. J Atheroscler Thromb 2012;19:999-1005.

79 Takaki A, Ogawa H, Wakeyama T, Iwami T, Kimura M, Hadano Y, et al: Cardio-ankle vascular index is superior to brachial-ankle pulse wave velocity as an index of arterial stiffness. Hypertens Res 2008;31:1347-1355. 